\title{
THE USE OF THE NATURALISM APPROACH IN DESIGNING THE TABRIZ CARPET MUSEUM
}

\author{
Amir Rishi Jegheh and Ardalan Karimi \\ Ilkhchi branch, Islamic Azad University, Ilkhchi, Iran
}

\begin{abstract}
Research Article

Culture and art have come from the very beginning of mankind, along with human life, in order to calm down humankind, and what comes out of mind in different arts and in different ways. With the advancement of mankind in various arenas and sciences, art,

PII: S238315531800003-7 in turn, was subject to change and in various parts of the earth's human races, the craftsmanship of buildings and handicrafts was made in caves. Meanwhile, art in the Middle East from ancient times was the cradle of human civilization and the creator and developer of human beings in various fields, including art. From ancient times, especially after the arrival of Islam, Iran has witnessed progress in various fields of literary culture, especially art and architecture. In addition to the art of building and architecture, the creation of motifs in the tiling of mosaics etc. Handmade carpet art is one of the characteristics of recognizing the art of the land of Iran, especially the territory of Azerbaijan. Tabriz is a Persian carpet garden with the texture and development of a variety of carpets in different designs with a fringe in the range and worldwide name in different parts of the world. It is worth mentioning that this ancient city has an exhibition or museums in which architecture along with art witnesses the display of authentic Iranian and Islamic art and architecture. In the post-industrial and post-modern era, we are studying and designing the spaces needed for the place. In addition to an indicator for the city of Tabriz, we have a very small footprint in reducing the heating of the earth and using indigenous and nature-friendly materials.

${ }^{\star}$ Corresponding author's e-mail: Ardalan_Karimi2003@yahoo.com
\end{abstract}

\section{KEYWORDS}

Museum, Carpet, Naturalism Architecture, Architectural Design

\section{INTRODUCTION}

One of the phenomenal phenomena in recent years is the growing trend of globalization. Our country is also seeking to join the World Trade Organization (WTO) in order to expand its non-oil exports and presence in global markets and is currently a member of the Organization's oversight body. One of the important industries that should be studied for this purpose is the handmade carpet. The export competitiveness index of handcrafted carpet 65 Isfahan silk rings is equal to 0.88 , indicating that the 65 handcrafted silk rings of Isfahan province are in competition with the current conditions in the global markets. Relative benchmark index is equal to 0.79 based on unit cost, which is the actual competitive advantage in free competition conditions after the accession of Iran to the WTO, and represents the relative advantage of the province in producing the carpet [1]. In the meantime, Tabriz has a special popularity. Tabriz Carpet is one of the types of Iranian carpets. This carpet is woven in the city of Tabriz [2]. This city is one of the most important centers of carpet weaving in Iran and its carpets have a lot of variety and variety. Tabriz is currently selected by the World Council for Handicrafts as the "World Carpet City" [3].

Undoubtedly, the existence of a museum as a cultural institution in the community is essential. The culture of every society is a general concept and embraces all the spiritual values and findings of the peoples of that society.

So the heritage culture is any ethnic group that has been taken from its predecessors and has been transformed into it and has been transmitted to subsequent generations. Cultures and civilizations, like humans, have three evolutionary stages:

They have a childhood and adolescence. They reach perfection and reach old age and eventually disappear. It takes the form of dynamic and necessary cultures and civilizations, takes over from other cultures, and throws away what is redundant.

\section{Maribota Speaks in Iran:}

My first attempt at designing and working on the project understands the subject. For example, when it comes to the museum, first of all I ask myself: "What is today's museum?" For me, there is an institution with a strong intellectual character. 
People go to the museum to ask artists and artwork. Therefore, the issue of spirituality is the spirituality that follows the forms of aesthetics [4]. At behind these forms of aesthetics is a moral tension that must be transmitted. For me, the museum today has the same function as the ancient cathedral, as the cathedral of contemporary world non-religious.

Such a reflection within the museum creates two heroes. The first hero is the visitor, and the second is the artwork to be discussed at the museum, so I will divide the space with this view into two seasons:

The space on which the visitor moves.

Mellow atmosphere in which the work of art is placed (and it should not be influenced by architectural artwork).

In the next step, while I have not yet done any lines, I try to search the site for a question. The earth and its condition respond well to us. I ask the earth what it's like to be? After that, the relation to the ground meets the concept, not the architectural form. And what matters to me is the relationship between architecture and the environment, not the form of architecture [5].

Humanity has evolved from the earth and has developed on Earth and in nature. Human handicrafts are inspired by nature and creation. The combination of art and architecture with the use of naturalism can create a natural art by combining the architectural mind. To emphasize the role of nature in the carpet with a construction that reflects this role along with the creative architecture of nature.

So at the beginning of the life, by studying the naturalistic approach and converting them into signals, we can see a general view of the subject.

The main question now is what is naturalism in architecture and how can it be used in designing the Tabriz carpet museum?

The overall aim of this research is to investigate naturalism in the design of the carpet museum.

In this research, it is tried to analyze the documents using comparative and analytical descriptive methods, and compare them with the similar designs and adapt the weaknesses and strengths.

\section{Methodology (data collection in this research)}

In this method, we examine the land in terms of its area and its gradients and its topography.

In the method of analyzing information, we try to quantitatively and qualitatively examine the content in terms of descriptive analysis, comparison, cause and effect, and to better design the subject.

\section{Define a museum or display house}

So far, no comprehensive theory of how the museum is described as a place is not expressed, of course, this does not mean that there is no proper understanding of what the museum is, because the museums that were built and the designs presented by the various designers each It can be argued that a museum without a definite definition can properly address all of the museums, and can be found, and each of its specific museums will be discovered and made available to republic [5].

\section{Types of museums}

Museums are categorized in a variety of ways, including historic and archaeological museums, outdoor museums, anthropological museums, palaces of museums, science and historical museums, regional museums, museums (Circulation), park museums, museum of weapons (military), museum of thinkers (house of artists) historical and archaeological museum: Historical view, representing historical dynasties. Most of these works are derived from archaeological excavations, representing the culture and the past of the past and integrating the science, art and knowledge of a nation or a nation. Such museums are also called mothers. The National Museum of Iran (Ancient Iran), the National Museum of Versailles in France, and the Museum of History in Washington are of this type.

Outdoor Museum: By creating these types of museums, important findings of the biostatistics can be made. The time of one scientific excavation of archaeology leads to the successful results and the discovery of valuable immovable works and cannot be transferred to museums, by providing the necessary conditions and facilities, they provide the place for public visibility. This is known as the Outdoor Museum. Among these, one can mention the Persepolis in Shiraz and the HegmatanehHistorical Site in Hamadan.

These museums are also common in other countries such as China, Greece and some other countries. In the province of Khorasan, the history of "Ghatyan" in Goz, which has very beautiful stylistics from the Sassanid period, as well as the historic site of "Shaykh" of Neyshabur, can be a good place for this.

Anthropological museums: culture, customs, beliefs, clothing, and social traditions prevailing in society. Tehran Museum of Anthropology and Ganjali Khan Bath are of this type.

Chamber of Commerce: The building is a historical monument that has come from our 
ancestors, and it expresses the status and manner of life of its owners. There may be historical objects as well as works of art, including painting on the wall, plastering, etc. The palace of the museums is usually created at the governmental centers, the purpose of which is the establishment of these museums to showcase the history of the museum as well as the study of Sadabad's palaces in Tehran and the Malek Abad Moshhad Gardens of these museums.

Art museums: There are a variety of visual and aesthetic arts exhibitions and usually have a lot of visitors, the Museum of Fine Arts in Tehran and the Museum of Decorative Arts in Isfahan.

Museum of Science and Natural Exhibitions: Scientific experiments are based on the evidence, and the natural and historical works and instruments that cover various plant species, especially avian species. The Natural History Museum of Isfahan and the Museum of Natural Sciences and Science of Mashhad are of this type.

Local or regional museums: represent the culture of a region or a particular neighborhood and only exhibit historical works and objects of the same area. The Museum of Susa, Persepolis and Tous Museum in Khorasan are of this type.

Mobile museums: To quickly advance cultural goals and due to the lack of opportunities in deprived areas and cities. These museum's exhibit diverse cultures in different places. If this kind of museum is enough, it will be very impressive.

Park Museums: Because of the various dimensions of science and culture, recreational and educational attractions, as well as entertainment, they are of great importance because they display natural and biological issues closely to the people. The important feature of these museums is that the general public can benefit from them. There is no museum park in Iran, but it is common in countries like China and North Korea.

The cultural, national and historical places like Ferdowsi's Tomb in Mashhad, the tomb of Attar and Khayyam in Neyshabur can be a good place to do so.

Museums of the Military: The historical process of the use of all kinds of military and military weapons is open to all. These types of objects include combat uniforms, guns and other combat gear.

The Museum of the Artists (House of Artists) is intended to offer artists, writers, inventors and inventors of the community, usually after their inception in their own homes, and includes personal belongings, tools and works of art, mostly in European countries It is common. Shakespeare's home is the famous English writer and Edison inventor of electricity in the United States of this type. In Iran, the large community of people, "Master Abolhassan Saba", has become a museum and includes paintings, publications and personal belongings [5].

\section{Carpet or rug}

Carpet or rug is a woven base from cotton, wool and, in some cases, silk, which is usually used to cover the earth. Since carpets and rugs have always had beautiful robes, today they are also considered to be decorative.

\section{Tabriz and carpet art}

With regard to the history of carpet in Tabriz, it can be said that according to the historic history of this city, the art of carpet weaving is in fact before the Safavid era. In the second half of the fifteenth century and during the Safavid period, the carpet turned into a state-of-the-art rural courtyard. Another important development in the carpet of this period was the designs created by the artists of the court of Tabriz and Herat. Ian Bennet's book "Rugs and Carpet of the World" finds another comment on the carpet of Tabriz during Safavid times, which is quoted here: "A large number of medallion or medley chunks that were in the early years of the 16th century under the rule of Shah Isma'il I And Shah Tahmasb are woven, have a Slavic design and animal and human designs. "In this book, the author has tried to attribute a number of carpets in the world's museums to the first half of the sixteenth century to Tabriz workshops from the 17th century. Subsequently, after the Iranian carpet was found abroad, the artisans of Tabriz, with the taste of the people of Europe and the United States, began to weave carpets that were very interesting and took the markets of those countries [6]. Tabriz is one of the most important knitting pillars of Iran in carpet weaving. Carpets, whether those that adorn the world's prestigious museums or are in an enthusiastic set of collectibles, or those that are on a large scale, in the quality of the market, are wellliked and well-liked. Compared to the statistics in Tabriz and its suburbs, in 1966, 16,000 carpet workers worked on 32,150 weaver workers. Plus Several workshops have been working on carpets since many years ago. In recent years Tabrizi knitters have been turning to the production of extremely delicate silk carpets with a range of 50 and 60 on a large scale. Such carpets, some of which are silken, are woven in mostly lacquer and bergamot designs, often with beige and light beige colors, and 
are used in coloring flowers and patterns of magenta, twig and olive [7]. Tabriz Carpets have been woven from the smallest to the largest possible size with potted designs, trees, almonds, gardens, animals, hunting grounds, Herat, horns, leafs, harpsichord, hangings, craftsmanship and geometric roles. The side texture and the flower is not very pleasant to Tabriz [2]. Nowadays, Tabriz is known as the main focus of the supply of marble carpets in Azerbaijan, and the main focus of the naming and naming companies is the Azerbaijani carpet. It is one of the most important knitting pillars of Iran in carpet weaving. Carpets, whether those that adorn the world's prestigious museums or are in an array of enthusiastic collectors, or those that are on a large scale and in a commercially viable market and fourway, are always lucid and customer-friendly [8].

\section{Naturalism}

Naturalism or naturalism is usually referred to as a philosophical belief that only the laws and forces of nature (not the laws and forces of the supernatural) are active in the world and are beyond the natural world. The followers of this idea are naturalistic or naturalistic, and themselves naturalistic or naturalistic. They believe that the natural laws that govern the structure and behavior of the natural world, and the creature universe is the same rules, and is intended to discover and disseminate the natural laws. Note that naturalists are also referred to those who engage in scientific research (or education) of nature and the natural world (especially animal and plant sciences), to distinguish those with particular philosophical functions. In this sense, "naturalist" and "eccentric" are synonymous with each other. The philosopher Paul Currents says the best way to describe the nature of the application of material principles, including the crime and other physical and chemical properties accepted by the scientific community. Moreover, the meaning of naturalism is that the spirit, the ghost, and the gods have no reality. Nature is not a goal. Usually this meaning of naturalism is called metaphysical or philosophical naturalism. God is an aversion to the idea that whatever nature is and no longer. Believe in gods or gods who have created nature. In theology they are also located and they are considered to be disabled by secondary causes. In the twentieth century, W. W. Kevin and George Stena, along with other philosophers, argued that the success of naturalism in science meant that scientific methods should be applied in philosophy. From this perspective, science and philosophy form a continuum [9].

\section{Nature-oriented architecture}

Nature-oriented architecture is not an imitation style, but an interpretation of the principles of nature for the creation of natural forms. Designers and architects have been inspired by nature to create their works. Or organic, not an imitation style, but an interpretation of the principles of nature to make natural forms. Engineers, designers and architects have inspired nature to create their work. An elaborate organic architecture is nature and principles that literally means the connection between the building and its surroundings, so that the building is combined with the site. In other words, the naturalist-oriented philosophy represents the harmony and adaptation of nature, man and place of residence, and the overall composition of the size of the architecture is such that the space inside and outside are integrated and integrated with nature from nature. Forms are a reflection of the landscape and features of the site, for example, buildings that are in the form of mountains and structures that are in the form of rivers and clouds. Architects are interested in imitation of nature not only to find new construction methods but also to find new inspirational sources for expressing aesthetics $[4,10]$.

The word "organic" is a natural word for something to happen, but in architecture it has a new meaning. Nature-oriented architecture is rooted in romantic philosophy, and romanticism is literally an artistic and philosophical movement in the late nineteenth and eighteenth centuries in the northwest of Europe that was transmitted to other parts of Europe and America. This movement is a response to the rationality of modern wisdom. In this context, all natural forms are dynamic. Organic architecture can be defined in nine stages: nature, organic, function, elegance, tradition, decorations, spirituality, and the third dimension of space. According to Frank Lloyd Wright, organic means the combination of the entire collection, and on organic buildings it is believed that architecture should be constructed based on the conditions of time, place, environment and purpose. Consider the Johnson Office Center Wax Designed by Frank Lloyd Wright, the pillars that climbed upward, beautifully expanded, and the upper portions of the rocks such as the lily float on a semi-transparent surface, create a realm underwater and a memorable atmosphere has created [10].

The nature-oriented architecture comes from a cultural tradition that is understandable through British romantic naturalism. The complete development of such a British culture in the United 
States has been characterized by the organic architecture of Frank Lloyd Wright, which gradually brings about a new idea of the relationship between humans and the environment The way in which architecture should manage relationships is also a way of striving for the ultimate sense of comfort and ease that lies in organic simplicity. In the contemporary era, the use of natural elements in residential spaces has become commonplace, for example, the presence of water and plants that provide a climate that is formed on the basis of regular geometries or the use of natural and native materials to reduce the cost of making and achieving Contemporary sustainable design has been effective [10-12].

Throughout his life on earth, man has recognized nature as a vital and mysterious source. And he always tried to discover all its dimensions, including the expression of nature in art. Nature has always been one of the most important inspirational sources of history throughout history. For example, the first remains of art in the caves. Aristotle; an ancient philosopher was one of the first people, who referred to nature as an inspirational source. Architects have used natural patterns in different ways in the process of designing a naturalistic architecture. The application and appropriate selection of native and natural materials and their application have caused. Those distinct architectures are created with the idea of naturalism. Frank Lloyd Wright, Alvarelle, Louis Kahn and Richardson are good examples of architects. This has optimized the quality of the use of natural materials in their projects [10].

\section{Man's relationship with nature in architecture}

The relationship between nature and man in architecture is based on architectural design in interaction with nature. Nature means comfort and tranquillity. If we design a building that has a nature-like behavior that is calm, then we can say that we have come to interact between architecture and nature [13].

\section{Natural restrictions}

Nature, despite its beauty and attractiveness, provides two limitations for humans:

Material constraints: Human beings cannot withstand all the conditions of nature and must separate from nature and refer to a different environment.
Theoretical limitations: Human insights and thoughts about defining the place of nature and its relation to humans define it above or below the human level.

Both of these factors create the architecture of different environments in the nature of nature [13].

\section{All kinds of ideologies related to nature}

Ideology of Controversial Nature (Facing Nature) (ideology of Confrontation)

Ideology of nature (indifferent) (separation from nature)

Nature-oriented ideology (becoming one with nature)

Naturalist ideology (Fragile Theory) (Completion Theory)

\section{Ideology of Controversial Nature}

The experience has been observed, when one uses a tool to overcome nature, the tool opens up against him and endangers him until the stage of destruction. The best example that can be mentioned is the use of nature tools to protect humans from natural hazards, to achieve more prosperity and to mechanize modern life, which in the same way irreversibly destroys human life through incidental audio, visual and the environment [13].

\section{Naturalistic practices in carpet museum architecture}

In our world, every new idea is rooted in the discovery of a number of hidden aspects of nature that are strikingly apparent through observation and revelation of natural variations.

1- Optimal use of materials

2. Maximization of structural power

3. Maximize the volume of enclosed space

4- Create the highest ratio of strength to structural weight

5- Use of stress and strain as the basis for structural performance

6. Creating efficient, energy-efficient, wellinsulated and convenient environments without the need to use external energy.

7. Creating forms to improve the airway colonization

8. Use of materials available on site to build

9. Use of curved shapes to disperse multidirectional forces

10. Increase aerodynamic efficiency by structural forms

11. No toxic and harmful substances to the environment 
12. Designing structures that can be built by a single organism

In the early part of the 2oth century, when Wright's ideas were gradually shaped in its buildings, technology was rapidly expanding in America and America. This advancement in the field of architecture was, in theory, very evident. Despite the fact that Wright was opposed to modern technology did not, but he did not consider it to be the ultimate goal. According to Wright, technology is a means to achieve a higher-level architecture that, to her mind, was an organic architecture. On May 20, 1953, he described Organic Architecture in Taliesin square-paper with the following statement [14]:

1. Nature: Only includes outside environment like clouds, trees.

2. Organic: means the integrity and integrity of the components relative to the whole and the whole component.

3. Functional form: Functional performance is not correct, but the combination of form and function, and the use of the invention of human thought in relation to the operation is essential. Form and function are one.

4. Thoroughness: Human thinking and thinking must form the hard materials of a building in a pleasant and humane form. As the tree and the trees cover their branches, the building must be

It is in the hands of man, and not in the opposite.

5- Tradition: Adherence and non-imitation of tradition is the basis of organic architecture.

6- Decorating: An integral part of architecture. The architecture of the detail is like the flowers to the branches of the plant.

7. Spirit: Soul is not something that is induced into a building, but it should be in it and it extends from outside to outside.

8. Third dimension: Contrary to popular belief, the third dimension is not width, but thickness and depth.

9. Space: An element that must be constantly expanded. The field is a putative foundation in which all rhythms of the building should come from it and flow therefrom.

Wright defines the term "organic architecture" with other terms such as dynamic, vital, intricate, and all-embracing, and identifies with these synonyms the term "organic", which is equivalent to the Persian "organ". Wikipedia English)

9. Design of the Carpet Museum of Tabriz with Naturalism
Design should create the bridge between nature and man. The design of the Carpet Museum of Tabriz with a nature-oriented approach is a completely climate-oriented and nature-oriented construction commensurate with the culture and identity of Tabriz. The computing design approach of this complex is such that the building is considered as part of nature and the surrounding area, taking into account the context of the formation of the angles and axes of the building, in order to create a complete harmony with the nature and history of the area.

The interaction between humans and space and nature is emphasized in the design of this collection to create a direct impact on the enthusiasm of visitors in feedback with this collection. The form and pattern of nature retain the type of visual power structure. The facade of the building is made up of indigenous materials whose pattern and form make a familiar sense of the cult of the visitors of the local traditions. With the interpretation and connection between the building, nature and man, the concept of "man and nature" is considered.

In the design of the interior, the continuous flow feature is evident from the design approaches with the concept of nature and naturalism. Crossing up the winding paths and guiding visitors to the arena, the showroom, the history hall, the art hall and carpet galleries create a variety of experiences. The nature, enthusiasm, and exploration of the building forces inspire visitors to fully understand the building, and this sense is functional in the body and set of plans.

\section{CONCLUSION}

There is no doubt that the art of designing and knitting carpets in Iran has become the full mirror of most of Iranian artistic insights throughout history. Nowadays, we know that the first sources of carpet art have been flooded from the foot of this frontier and, in the history of history, has swept across the universe from its delicate artifacts. The Iranian dialect, including the Tabriz carpet, as a manifestation of the paradise of an unbreakable bond with customs, traditions, The culture and religion of the people of this land have been and has been and throughout history, along with the cultural and social changes of the people of this land has grown and has grown. Here it is worth mentioning from the master of art of carpet weaving of Iran, the late Razam Arabzadeh in the Quarterly Journal of Art We promise them; an oath that whispered the Mahjouri's art of carpet weaving; All, the mother of 
all the traditional arts of this land, with all the words of his fertility and survivor, and the great hadeeth of love hidden in his womb, is so obscure and obscure. Tabriz, as a carpet garden in Iran, deserves a museum to showcase this art to the world. Beside this exhibition, attention will be given to naturalism and inspiration from our nature in the design of nature. By studying design records, we need to come up with a general conclusion about the design and creation of such a space.

\section{DECLARATIONS}

\section{Acknowledgments}

At the end, it is necessary to give thanks to the Islamic Azad University - Ilkhchi branch. This article is summarized from Thesis of first author in this university.

\section{Competing interests}

The authors declare that there is no competing interests.

\section{REFERENCE}

[1] Yousefvand S (2016). The Islamic Republic of IRAN Accession to the WTO. Accession to the World Trade Organization. Ashgabat, May 206. https://www.wto.org/english/thewto e/acc e/iran s esssion1_e.pdf

[2] Jafari F (1999). Tabriz Carpet Museum, Thesis, Master of Architecture, Islamic Azad University, Tabriz Branch, Tabriz.

[3] http://hamshahrionline.ir (accessed: 2018)
[4] Parvizi M and Karami I (2015). Principles of Islamic aesthetics in the physical and spatial structure of Iran's banana (Case study: Tehran carpet museum), National Iranian Architecture and Urban Planning Conference, Rasht, Payam Noor University of Guilan Province.

[5] Safari T, Acharya S, Urano S (2011). Inventors; Kubisys Inc., assignee. Processing requests in virtual computing environments. United States patent US 7,962,620. Link, Google Scholar

[6] Goswami KK (2018). Developments in handmade carpets: Introduction. Advances in carpet manufacture (pp. 213-268). Woodhead Publishing. https://doi.org/10.1016/B978-0-08-101131-7.00011-3 , Google Scholar

[7] Karimi Azari AR and Obshdar A (2014). Analysis of the role of color and light in the transfer of architectural concepts of carpet museums as the Persian carpet identity, International Conference on Civil Engineering, Architecture and Urban Infrastructure, Permanent Conference Secretariat . Tabriz.

[8] Nasiri M (2010). Immortal legend of Iranian carpet. Mirdashti Cultural Center Publication, Tehran, Iran.

[9] Retrieved from Persian Wikipedia website, (2018)

[10] http://4sooarc.com

[11] Breheny M (1993). Planning the sustainable city region. Town \& Country Planning. 62(4):71-5. Google $\underline{\text { Scholar }}$

[12] Smit J and Nasr J (1992). Urban agriculture for sustainable cities: using wastes and idle land and water bodies as resources. Environment and urbanization. 4(2):141-52. Google Scholar , https://doi.org/10.1177/095624789200400214

[13] Bahrain, SH, (1997), Urban Development and Sustainable Development, Approach, No. 17

[14] Wright FL (1953). Language of an Organic Architecture (Book). [Spring Green, Wisc.] Series: Taliesin square-paper, 16. Google Scholar, Worldcat 